\title{
A NARRATIVA AUTOBIOGRÁFICA DE INFÂNCIA: ARREBATADOS PELOS SENTIDOS EM L'ODEUR DU CAFÉ, DE DANY LAFERRIÈRE
}

\author{
Ataiena V. da L. Miguel Sobrinho ${ }^{1}$
}

\section{RESUMO:}

Neste artigo, abordamos uma autobiografia de infância, L'Odeur du café, de Dany Laferrière, escritor de língua francesa associado à dita literatura migrante. No primeiro item, discutimos considerações teóricas essenciais para se definir a narrativa autobiográfica de infância, tendo em vista a noção de história de vida e elementos pontuais da unidade biográfica e, em particular, das lembranças de infância. Em seguida, apresentamos o escritor Dany Laferrière e discorremos sobre o contexto de sua produção artística e cultural, caracterizada por uma poética híbrida escrita numa língua francesa reinventada. Por fim, apresentamos especificidades de L'Odeur du café, tais como a predominância do tempo presente, fato inabitual na narrativa em língua francesa, o recurso de uma retórica da sinceridade, traços da língua crioula e, principalmente, associações do livro com elementos da estética da pintura naïf.

PALAVRAS-CHAVE: Autobiografia de infância, Dany Laferrière, literatura migrante, pintura naif.

\begin{abstract}
:
In this paper, we discuss a childhood autobiography, L'Odeur du café, of Dany Laferrière, French language writer usually associated with what is known as "migrant literature". In the first item, we discuss essential theoretical issues in order to define the autobiographical narrative of childhood, taking into consideration the notion of life history and specific elements of the biographic unit, in particular, childhood memories. Next, we present the writer Dany Laferrière and we discuss the context of his cultural and artistic production, characterized by a hybrid type of poetics written in reinvented French. Finally, we present some of the characteristics of L'Odeur du café, such as the predominance of present tense - an unusual fact in the French narrative — the use of a rhetoric of sincerity, some traits of Creole and, finally, some of the associations between the book and elements of Naif painting.
\end{abstract}

KEYWORDS: Childhood autobiography, Dany Laferrière, migrant literature, Naif painting.

Este artigo originou-se a partir de uma pesquisa desenvolvida na área de didática de línguas estrangeiras, na qual refletimos sobre o trabalho com a leitura de uma obra literária integral em sala de aula, e analisamos a recepção de um universo de vinte leitores, alunos de Francês Língua Estrangeira (FLE), suas representações de mundo e suas interpretações. Ao trabalharmos com o texto literário, tornou-se indispensável o enfoque mais detalhado sobre o caráter plural e conotativo deste corpus, seu prazer estético, e a descoberta perturbadora do outro na leitura literária. Pelo fato de termos trabalhado especificamente com uma autobiografia de infância de Dany Laferrière, L'Odeur du café, vencedor do Prix Carbet de la Caraibe em 1991, tivemos o privilégio de mergulhar nos domínios teóricos do gênero autobiográfico, assim como no estudo do estilo do autor, em seus métodos de trabalho, no contexto em que sua produção se insere e na singularidade da obra escolhida. Deste trabalho, concebido inicialmente como um questionamento de como se trabalhar com profundidade o potencial polissêmico do texto literário com leitores em língua estrangeira, nasceu nossa pesquisa literária, e a necessidade de

\footnotetext{
${ }^{1}$ Ataiena V. da L. Miguel Sobrinho é Mestre em Língua e Literatura Francesa pela Faculdade de Filosofia, Letras e Ciências Humanas da Universidade de São Paulo. Sua dissertação, A autobiografia de infância em sala de aula de língua estrangeira: o sabor das leituras de L'Odeur du café, de Dany Laferrière, está disponível no site www.teses.usp.br. Atualmente, ela leciona na Aliança Francesa de São Paulo. Contato: ataiena@usp.br.
} 
aprofundá-la. Podemos dizer que fomos arrebatados, como permitimo-nos dizer no título deste artigo; e queremos agora arrebatar mais leitores para este mundo naï com que nos deparamos em nossas investigações, de agora em diante, predominante e inevitavelmente, literárias.

\section{A narrativa autobiográfica de infância: considerações teóricas}

"Enfance, c'est richesse dont jamais tu n'accordes géographie très claire.”2

(CHAMOISEAU, 1990, p. 21)

Infância. Récit d'enfance. Como narrar a infância através dos olhos de um escritor-narradorpersonagem adulto, distanciado no tempo, nas emoções e nas sensações? Mais do que isto, por que narrar a infância? Seria realmente possível encontrar na infância as chaves da identidade adulta? Um projeto aparentemente improvável devido às nossas inúmeras limitações de indivíduo adulto, as quais não apreendem mais a riqueza daquela geografia ilimitada... infância. Freud aponta justamente a instabilidade e a dificuldade para delimitarem-se as lembranças de infância:

Muito diferente das lembranças da idade adulta, elas [as lembranças de infância] não se fixam no momento da experiência para mais tarde serem repetidas; somente surgem muito mais tarde, quando a infância já acabou; nesse processo, sofrem alterações e falsificações de acordo com os interesses de tendências ulteriores, de maneira que, de um modo geral, não poderão ser claramente diferenciadas de fantasias. (FREUD, 1969 , p. 77)

Para entendermos o que é uma narrativa de infância, não podemos deixar de considerar o que é um discurso autobiográfico, pois ela é um discurso autobiográfico de busca iniciativa, empreendida pelo autor adulto da própria infância. Para isto, retomamos alguns pressupostos básicos que Philippe Lejeune (2004, p.10) indica para uma possível definição de autobiografia: "chamamos autobiografia a narrativa introspectiva em prosa que alguém faz de sua própria existência, quando ele enfatiza sua vida individual, em particular a história de sua personalidade.” Lejeune ressalta ainda que esta definição nos remete a três categorias: a forma da linguagem, o assunto tratado e a situação do autor; a forma da linguagem seria a narrativa em prosa, o assunto tratado, a história de um indivíduo, e quanto à situação do autor, haveria a identidade do autor, do narrador e do personagem numa narrativa retrospectiva.

As categorias reunidas acima e apresentadas por Lejeune definem o discurso autobiográfico de um ponto de vista formal. Seriam elementos ideais dentro de uma composição ideal de texto autobiográfico. Vale ressaltar que eles são bastante pertinentes e, de fato, dão conta da maioria das produções dentro do domínio da autobiografia. No entanto, como ocorre com toda regra que tenta estabelecer as diretrizes classificatórias de uma determinada área, não serão todos os autores que se "enquadrarão" nesta definição, como veremos mais adiante com a introdução da narrativa de Dany Laferrière, L'Odeur du café. Somente os elementos formais de definição do discurso autobiográfico não

\footnotetext{
${ }^{2}$ Todas as traduções presentes neste artigo são minhas: "Infância é riqueza de que jamais você recorda geografia muito clara"
} 
são, portanto, suficientes para defini-lo enquanto tal. Por isto, consideraremos a noção de história de vida ou história de uma vida proposta por Pierre Bourdieu:

Falar de história de vida é pelo menos pressupor - e isso não é pouco - que a vida é uma história e que [...] uma vida é inseparavelmente o conjunto dos acontecimentos de uma existência individual concebida como uma história e o relato dessa história.

[...] Sem dúvida, cabe supor que o relato autobiográfico se baseia sempre, ou pelo menos em parte, na preocupação de dar sentido, de tornar razoável, de extrair uma lógica ao mesmo tempo retrospectiva e prospectiva, uma consistência e uma constância, estabelecendo relações inteligíveis, como a do efeito à causa eficiente ou final, entre os estados sucessivos, assim constituídos em etapas de um desenvolvimento necessário. (BOURDIEU, 1996, p. 183 e 184)

Por outro lado, Bakhtin fala preferencialmente de uma unidade biográfica mais do que uma história de vida, no sentido em que os valores da estética da vida (re)constituem "um quadro minimamente inteligível e coerente de minha vida e de seu mundo". (Bakhtin, 2006, p.139 e p.141) Isto é, para Bakhtin, a pergunta a se fazer é “como eu represento a mim mesmo?" e não "quem sou?": para representar-se a si mesmo, é necessário reunir os valores biográficos de que tomamos conhecimento pela boca de outras pessoas, familiares, pessoas próximas. Desta forma, tornamo-nos personagens da narração de nossa própria vida, na tentativa de compormos a unidade biográfica da vida, formada pelos fragmentos, valores da estética da vida, de uma vida que flui, e (re)constituídos pelos outros para serem reunidos pela consciência do narrador:

Ao narrar sobre minha vida cujas personagens são os outros para mim, passo a passo eu me entrelaço em sua estrutura formal da vida (não sou o herói da minha vida mas tomo parte nela), coloco-me na condição de personagem, abranjo a mim mesmo com minha narração [...] Tomo conhecimento de uma parte considerável da minha biografia através das palavras alheias das pessoas íntimas e em sua tonalidade emocional: meu nascimento, minha origem, os acontecimentos da vida familiar e nacional na minha tenra infância [...] Sem essas narrações dos outros, minha vida não seria só desprovida de plenitude de conteúdo e de clareza como ainda ficaria interiormente dispersa, sem unidade biográfica axiológica. (BAKHTIN, 2006, p. 141 142)

Esta consistência e constância, que não são óbvias nem facilmente alcançadas, só podem ser estabelecidas pela conexão imprevisível de diversos fragmentos de um "eu", numa busca cuja única finalidade é, na verdade, assegurar sua coerência (da forma o mais integral possível), o que pressupõe, portanto, reencontrar sua gênese na infância. Na narrativa autobiográfica de infância, o "eu” busca na sua origem as chaves da identidade adulta. Lejeune (1998) faz questão de lembrar o papel inegável da infância na significação do "eu", assim como a dificuldade de (re)apreender esta(s) origem(ns) primeira(s) ao dizer que a psicanálise nos mostra que "tudo (ou muito) se passa nos primeiros anos, esquecendo que

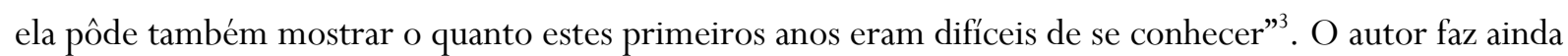
as seguintes considerações sobre a natureza profunda das recordações e a narrativa de infância:

\footnotetext{
3 "Tout (ou beaucoup) se joue dans les premières années, en oubliant qu'elle a pu aussi montrer combien ces premières années étaient difficiles à connaître."
} 
As lembranças de infância são descontínuas e incertas, mas frequentemente intensas [...] Mergulha-se diretamente no fundo de si, numa fonte de vida. É por isto que o regime banal da lembrança de infância é o lirismo. Está-se no domínio da fé.

[...] A narrativa de infância se apresenta, então, como uma busca iniciática, da qual se mostram as dificuldades. A memória é fragmentada, as lembranças flutuam [...] É o estremecer da memória [...] $]^{4}$ (LEJEUNE, 1998, p. 3 6)

Os elementos apontados por Lejeune encontram-se com o que Bakhtin chama de credulidade ingênua no mundo inconcluso da biografia (ou autobiografia):

O mundo da biografia não é fechado nem concluído, não está isolado do acontecimento único e singular da existência por fronteiras sólidas e de princípio. [...] A vida biográfica e a enunciação biográfica são sempre cercadas de uma fé ingênua, seu clima é quente; a biografia é profundamente crédula mas de uma credulidade ingênua (sem crises) (BAKHTIN, 2006, p. 152)

Assim, a narrativa de infância constitui uma tipologia especial de narrativa autobiográfica que não se propõe a recuperar "ingenuamente" uma infância perdida no tempo, mas sim a revivificar uma etapa indispensável para se compor o extenso e complexo quadro da história de uma vida. Freud já apontava em seus estudos: "O que alguém crê lembrar da infância não pode ser considerado com indiferença; como regra geral, os restos de recordações — que ele próprio não compreende — encobrem valiosos testemunhos dos traços mais importantes de seu desenvolvimento mental” (Freud, 1969, p. 78). Estes traços, apontados por Freud como "restos de recordações”, constituem o quadro de uma busca incerta e frágil, que sofre frequentemente rupturas causadas pelas lacunas da memória seletiva, parcial e imprevisível, numa reconstituição de fé ingênua do rio da infância; rio que deságua no mar da vida adulta, para compor, enfim, a geografia de uma vida. E quando este mar da vida adulta está entre dois mundos e a geografia desta vida corresponde a uma identidade plural? É o que veremos a seguir com Dany Laferrière.

\section{A narrativa autobiográfica de infância de Dany Laferrière}

\subsection{Um autor migrante ou um autor sem fronteiras?}

A escrita de autores haitianos que vivem e publicam no Quebec constitui atualmente um novo campo de estudos em literatura. Na verdade, ela se insere num horizonte bem maior, que remete às obras dos escritores ditos migrantes no Quebec, ou seja, na literatura migrante, cujo corpus constitui, na verdade, uma literatura em construção, que escapa a definições (de)limitantes. Atribui-se frequentemente a este universo o tema do exílio, partindo-se da dualidade, o entre-dois mundos, à expressão de uma identidade plural e à configuração de uma escritura híbrida. Monique Lebrun (2007)

\footnotetext{
4 "Les souvenirs d'enfance sont discontinus et incertains, mais souvent intenses [...] On puise directement au fond de soi, à une source de vie. C'est pourquoi le régime ordinaire du souvenir d'enfance est le lyrisme. On est dans le domaine de la foi.

[...] Le récit d'enfance se présente donc souvent comme une quête initiatique, dont on met en scène les difficultés. La mémoire est morcelée, les souvenirs flottent [...] C’est le tremblé de la mémoire”
} 
nota que o conceito atual de literatura migrante no Quebec se delimitou há cerca de quinze anos e Clément Moisan (2004, p. 93), retomando Pierre Nepveu, estudioso do tema na década de 80, aponta que o termo migrante insiste principalmente sobre "o movimento, a deriva, os cruzamentos múltiplos que suscita a experiência do exílio".

Já Joëlle Vitiello (1996) observa que a dificuldade em se definir estes escritos (literatura de exílio, literatura migrante, literatura haitiana, no caso dos escritores nascidos no Haiti, ou literatura do Quebec) constitui uma questão complexa nos estudos atuais sobre o tema. A autora evidencia ainda que "Esta necessidade de ser identificado nacional e culturalmente só pode trazer problemas suplementares aos autores 'deslocados', cuja literatura é percebida como sendo 'de fora'”, nem do Quebec, nem do país natal, mas sim deste espaço de fora (VITIELLO, 1996, p. 350). Neste contexto, instala-se o escritor pluricultural, "à busca de sua coerência através de suas experiências em várias línguas e culturas" (LEBRUN, 2007, p. 14).

No momento em que vivemos os efeitos e polêmicas da globalização e da concorrência econômica internacional, as diversas áreas do conhecimento voltam-se justamente para a diversidade e a pluralidade. Neste contexto, pensar o outro torna-se uma necessidade intrínseca para a tomada de consciência sobre possíveis olhares etnocentrados e estereotipantes, na tentativa de chegar-se a uma descentralização que permita um olhar redefinidor, capaz de ser relativo diante da(s) diferença(s). Assim, perceber e entender o outro na complexidade de nossa época conduz-nos ao triunfo dos prefixos em ciências humanas (GOHARD-RADENKOVIC, 2005), tais como multicultural, pluricultural, intercultural, transcultural, transnacional, todos presentes nos estudos teóricos sobre a literatura migrante.

Neste contexto de produção artística e cultural, Dany Laferrière aparece como um expoente de uma escritura híbrida e plural no espaço dos escritores migrantes: "Nasci fisicamente no Haiti, mas nasci como escritor em Montreal”' (LAFERRIÈRE apud VITIELLO, 1996, p. 354). O resultado: uma obra, grandemente autobiográfica, que recria e reinventa o real, escrita entre o Haiti, Montreal e Miami, (visto que o autor passou seus primeiros vinte e três anos no Haiti, e cerca de trinta, até os dias atuais, entre Montreal e Miami), inserida num universo de travessia de línguas, de territórios e do imaginário, que Laferrière recusa-se, resolutamente, a delimitar: "O fato é que me perco nesta confusão linguística. Sou atravessado por diferentes línguas, por diferentes costumes, por diferentes histórias, que fazem uma guerra incessante para saber quem vai dominar meu espírito" (LAFERRIÈRE, 2000, p. 181) ${ }^{6}$. Ou ainda, confundindo e embaralhando todas as pistas de uma possível classificação de sua obra literária:

tenho vários chapéus. Sou também tudo que não quero ser. Sou um escritor haitiano, um escritor caribenho (o que é levemente diferente de um escritor antilhano, mas sou também um escritor antilhano), um escritor quebequense, um escritor canadense e um escritor afro-canadense, um escritor americano e um escritor afro-americano, e há pouco tempo, um escritor francês (LAFERRIÈRE, 2000, p. 94) ${ }^{7}$.

\footnotetext{
${ }^{5} \mathrm{O}$ autor nasceu em 1953 no Haiti e publicou seu primeiro livro, Comment faire l'amour avec un nègre sans se fatiguer, em 1985, Montreal, VLB.

6 "Le fait est que je me perds dans ce fouillis linguistique. Je suis traversé par différentes langues, par différentes coutumes, par différentes histoires, qui se livrent une guerre incessante pour savoir qui va dominer mon esprit”.

7 “j'ai plusieurs chapeaux. Je suis aussi tout ce que je ne veux pas être. Je suis un écrivain haïtien, un écrivain caraibéen (ce qui est légèrement différent d'un écrivain antillais, mais je suis aussi un écrivain antillais), un
} 
A recusa das diversas "etiquetas" pelo autor abrange também a de escritor francófono: "As pessoas me perguntam por que sou visceralmente contra a francofonia? Eis uma das razões: não quero mais uma fronteira." (LAFERRIÈRE, 2000, p. 72) Não apenas Laferrière, mas também cerca de quarenta outros expoentes de literaturas e culturas de expressão francesa, que recusam a classificação de escritor francófono, como ele, assinaram o manifesto Pour une "littérature-monde"en français, publicado na edição do jornal Le Monde de 15/03/2007. O objetivo principal do manifesto, assinado também por Laferrière, é o de reivindicar uma literatura sem fronteiras, isto é, sem a limitação da classificação "francophone", que remete, por si só, a um passado colonialista e, portanto, a um quadro pós-colonial.

Sejamos claros: a emergência de uma literatura-mundo em língua francesa conscientemente afirmada, aberta sobre o mundo, transnacional, assina o ato de falecimento da francofonia. Ninguém fala o francófono, nem escreve em francófono. [...]

Literatura-mundo, porque, certamente, múltiplas, diversas, são hoje as literaturas de língua francesas pelo mundo, formando um vasto conjunto cujas ramificações enlaçam vários continentes. ${ }^{8}$ (BARBÉRY et alii 2007 p.2)

Ramificações que remetem à pluralidade artística e cultural de uma grande produção em língua francesa, assim como a obra de Laferrière; obra que alcançou aos olhos da crítica a dimensão de uma vasta Autobiografia americana, formada por dez romances (aos quais o autor insiste em referir-se usando "um", para designar o conjunto da obra). Inicialmente, uma preferência do autor, o termo "uma Autobiografia americana” foi, posteriormente, aceito e reproduzido de maneira bastante recorrente pela mídia e crítica especializada para designar uma identidade fortemente autobiográfica de "homem do Novo Mundo”, já que Laferrièe rejeita toda tentativa de categorização geográfica:

Reagrupada sob o título de Autobiografia americana, a obra romanesca de Dany Laferrière conta com dez obras produzidas entre os anos 1985 e 2000. ${ }^{9}$ Se os diversos textos compartilham todos o desejo de inscrever a figura identitária do autor no vasto território do Novo Mundo — de habitá-lo, de alguma forma —, seu percurso é um que poderíamos qualificar de migratório. A metáfora empregada aqui [...] reenvia preferencialmente a uma movimentação voluntária e periódica, uma navigação que caracteriza ao mesmo tempo o modo de vida do autor e a arquitetura romanesca da sua obra.

[...] a obra romanesca de Laferrière se desdobra, assim, entre Montreal, Estados Unidos e Haiti, fazendo a ida e vinda entre estes três lugares geográficos, mas também entre estes espaços simbólicos (LAZURE e ROYER, 2006, p. 17) ${ }^{10}$.

écrivain québécois, un écrivain canadien et un écrivain afro-canadien, un écrivain américain et un écrivain afroaméricain, et, depuis peu, un écrivain français".

8 “Soyons clairs : l'émergence d'une littérature-monde en langue française consciemment affirmée, ouverte sur le monde, transnationale, signe l'acte de décès de la francophonie. Personne ne parle le francophone, ni n'écrit en francophone. [...]

Littérature-monde parce que, à l'évidence multiples, diverses, sont aujourd'hui les littératures de langue françaises de par le monde, formant un vaste ensemble dont les ramifications enlacent plusieurs continents.”

9 Em ordem de publicação: Comment faire l'amour avec un Nègre sans se fatiguer (1985), Éroshima (1987), L'Odeur du café (1991), Le goût des jeunes filles (1992), Cette grenade dans la main du jeune Nègre est-elle une arme ou un fruit? (1993), Chronique de la dérive douce (1994), Pays sans chapeau (1996), La chair du maître (1997), Le charme des aprèsmidi sans fin (1997) e Le cri des oiseaux fous (2000).

10 "Regroupée sous le titre d'Autobiographie américaine, l'œuvre romanesque de Dany Laferrière compte dix ouvrages produits entre les années 1985 et 2000. Si les divers textes partagent tous le désir d'inscrire la figure 
Acreditamos que um dos aspectos determinantes para que a obra de Laferrière atingisse (até o momento atual) esta concordância crítica deve-se, dentre muitos aspectos, à uma escrita pincelada, subjetiva, e (auto)biográfica das emoções do indivíduo-autor com a intenção de ressaltar a história de uma vida:

[...] meu trabalho não consiste em dizer os fatos, mas preferencialmente em fazer surgir a emoção de uma situação. Para mim, é a verdade da emoção que conta, e nada mais.[...] pinto preferencialmente as coisas tais como as sinto [...] trata-se somente de mim, e é desta forma que tenho uma chance de interessar os outros. Quanto mais escrevo próximo de meu coração, mais risco de tocar o universal (LAFERRIÈRE, 2000, p. 36) ${ }^{11}$.

Vitiello (1996, p. 352) aponta o que chama de espaço haitiano-quebequense como o possível representante de "um espaço e um momento imaginários, constitutivo de uma memória local temporária, cujas poéticas fragmentadas oscilam do particular ao universal, do transitório ao traço inextinguível da hibridez".

Feitas todas estas considerações sobre a pluralidade da identidade de Dany Laferrière, falemos agora com mais detalhes de L'Odeur du café e da escrita de Laferrière.

\section{L'Odeur du café}

“[...] j'ai écrit ce livre pour cette seule raison qui m’a poursuivi si longtemps: un petit garçon assis aux pieds de sa grand-mère sur la galerie ensoleillée d'une petite ville de province”" (LAFERRIÈRE, 2001, p. 226-227) ${ }^{12}$.

\subsection{O caloroso presente do indicativo}

Vejamos a introdução da narrativa de infância de Laferrière :

LA GALERIE

\section{L'été 63}

J'ai passé mon enfance à Petit-Gôave, à quelques kilomètres de Port-au-Prince. Si vous prenez la nationale Sud, c'est un peu après le terrible morne Tapion. Laissez

\footnotetext{
identitaire de l'auteur dans le vaste territoire du Nouveau Monde de l'habiter, en quelque sorte -, son parcours en est un que l'on pourrait qualifier de migratoire. La métaphore employée ici (...) renvoie plutôt à une mouvance volontaire et périodique, une navigation qui caractérise tout à la fois le mode de vie de l'auteur et l'architecture romanesque de son œuvre.

[...] l'œuvre romanesque de Laferrière se déploie donc entre Montréal, les États-Unis et Haiti, faisant l'allerretour entre ces trois lieux géographiques, mais aussi entre ces espaces symboliques"

${ }^{11}[\ldots]$ mon travail ne consiste pas à dire les faits mais plutôt à faire surgir l'émotion d'une situation. Pour moi, c'est la vérité de l'émotion qui compte, et rien d'autre. [...] je peins les choses telles que je les ressens [...] il ne s'agit que de moi, et c'est comme ça que j'ai une chance d'intéresser les autres. Plus j'écris proche de mon cœur, plus je risque de toucher à l'universel".

12 “[...] escrevi este livro por esta única razão que me perseguiu durante tanto tempo: um pequeno menino sentado aos pés de sua avó no terraço ensolarado de uma pequena cidade do interior”.
} 
rouler votre camion (on voyage en camion, bien sûr) jusqu'aux casernes (jaune feu), tournez tranquillement à gauche, une légère pente à grimper, et essayez de vous arrêter au 88 de la rue Lamarre.

Il est fort possible que vous voyiez, assis sur la galerie, une vieille dame au viasage serein et souriant à côté d'un petit garçon de dix ans. La vieille dame, c'est ma grandmère. Il faut l'appeler Da. Da tout court. L'enfant, c'est moi. Et c'est l'été 63. (LAFERRIÈRE, 2001, p. 15)

Vimos com Lejeune que uma das categorias convencionais na composição do texto autobiográfico é a perspectiva retrospectiva da narrativa. Entretanto, a narrativa de Laferrière, embora comece de maneira retrospectiva (J'ai passé mon enfance à Petit-Gôave), passa rapidamente para a perspectiva de uma narrativa no presente que nos diz "estamos no verão de 63". Como explicar o recurso narrativo empregado principalmente no segundo parágrafo, que passa da descrição pincelada de uma imagem da infância do autor-narrador para a situação temporal “L'enfant, c'est moi. Et c'est l'été 63"? O primeiro passo para entendermos o jogo narrativo de L'Odeur du café é notar que o narrador nos traz para uma narrativa predominantemente presente, em que verbos no presente e no passé composé alternam-se, cedendo muito pouco espaço ao passé simple, que deveria ser, essencialmente, o tempo predominante da narrativa em francês, mas não na de Laferrière. O autor mesmo diz em sua entrevista com Bernard Magnier, posteriormente escrita e publicada pelo próprio Laferrière (2000, p.14) "gosto do quente presente do indicativo", e quando perguntado sobre sua composição narrativa em L'Odeur du café, responde que

L'Odeur du café é escrito no presente do indicativo. Jamais quis fazer uma recriação do passado, quis em cada vez reviver minha infância. O presente é um tempo em que me sinto bem. [...]

[...] Quando era pequeno, só gostava das histórias que se passavam no presente. [...] Detestava as lendas. Na verdade, o presente, para mim, é a vida. Então, quando escrevo meus livros, organizo-me sempre para reencontrar o presente. L'Odeur du café começa no passado [...], mas muito rapidamente, entra-se no presente. ${ }^{13}$ (LAFERRIÈRE, 2000, p. 157)

Reencontrando, assim, o presente, o narrador-criança toma a frente da narrativa desde as primeiras linhas, deixando muito pouco espaço para que o autor-narrador adulto rememore a infância; esta travessia espacial e temporal se dá pela "reconstrução do olhar da criança" (VITIELLO, 1996) e o leitor é seduzido a aceitar o foco narrativo desde as primeiras linhas: "L'enfant, c'est moi. Et c'est l'été 63”. O narrador-criança se impõe definitivamente e, a partir de então, dificilmente se questiona a exatidão do texto, criando-se a ilusão de um livro narrado pelos olhos de uma criança. Vemo-nos frequentemente no meio dos diálogos e das emoções infantis:

Didi est amoureuse de Frantz. Je le sais parce qu'elle ne le regarde jamais. Elle fait comme s'il n'existait pas.

\footnotetext{
13 “L’Odeur du café est écrit au présent de l'indicatif. Je n’ai jamais voulu faire une recréation du passé, j'ai voulu à chaque fois revivre mon enfance. Le présent est un temps où je me sens bien. [...] Quand j'étais petit, je n'aimais que les histoires qui se passaient au présent. [...] Je détestait les légendes. En fait, le présent, pour moi, c'est la vie. Alors, quand j'écris mes livres, je m'arrange pour retrouver le présent. L'Odeur du café commence au présent [...], mais, très rapidement, on entre dans le présent.”
} 
Vava fait la même chose avec moi, mais c'est pas pour la même raison. (LAFERRIÈRE, 2001, p. 128)

Não é necessário que um narrador adulto nos explique que o menino sofria com a indiferença de Vava, “ce brûlant premier amour”, como nos será dito na página final da narrativa; o sentimento está lá, no presente revivido da narrativa.

Em breves momentos, há uma indicação temporal indicando que o narrador está em outro tempo e não no presente do verão 63:

Quand on y pense bien, il ne s'est rien passé cet été, sinon que j’ai eu dix ans. Il faut dire que j'ai été un peu malade, j'ai eu de fortes fièvres, et c'est pour cela que vous

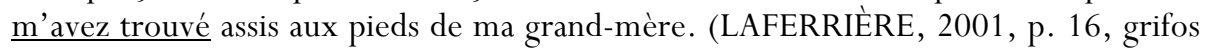
meus)

No entanto, embora os verbos indiquem o passado, contrariamente à indicação inicial da narrativa “c'est l'été 63”, predomina ainda a utilização do passé composé e não do passé simple (que marcaria definitivamente uma ruptura temporal com o presente da narrativa).

\subsection{O recurso da sinceridade}

$\mathrm{Na}$ extensão de sua obra, e em especial, em sua narrativa de infância, Laferrière não recorre, por exemplo, a uma explícita exaltação da memória (ou às lacunas da memória) ou ao tom de confissão, como procedimento retórico, para marcar a fragmentação das lembranças. Ao invés da retórica da sinceridade, ele prefere o recurso da sinceridade, o qual chama de "artifício da sinceridade”:

Em literatura, a sinceridade é o primeiro artifício. [...] Você pode ser sincero, mas não é suficiente para que acreditem em você, e para isto você só dispõe de um lápis e de um pedaço de papel como todo mundo. Para colocar em cena 60\% de sinceridade e 40\% de artifício. A verdade precisa ser verossímil (LAFERRIÈRE, 2000, p. 97) ${ }^{14}$.

O autor, por trás da escrita autobiográfica, reconhece, portanto, que é necessário estabelecer uma verdade verossímil, cuja aparência de sinceridade é alcançada pelo artifício. A “confissão” de Laferrière não constitui, na verdade, uma surpresa. Vimos com Bakhtin que, para se atingir a unidade biográfica, é necessário reconstituir um “quadro minimamente inteligível e coerente” da vida. Vimos também com Bakhtin que, ao se narrar a própria vida, não se é o herói dela, mas sim uma personagem, personagem da nossa própria história de vida, cuja percepção de grande parte da biografia ocorre através das palavras de outrem, pessoas íntimas e/ou do círculo familiar (“personagens de minha vida”). Já Lejeune, como mencionado anteriormente, lembra que a psicanálise aponta que muito da significação do “eu” se deve aos primeiros anos da infância.

Laferrière opta por não tentar reconstruir o quadro de sua tenra infância; não há menção de elementos de seu nascimento, círculo familiar e experiências na tenra infância (não se trata aqui da

\footnotetext{
14 “En littérature, la sincérité est le premier artifice. [...] Tu peux être sincère, mais ce n'est pas suffisant pour qu'on te croie, et pour cela tu ne dispose que d'un crayon et d'un morceau de papier comme tout le monde. Pour mettre en scène $60 \%$ de sincérité, il faut $40 \%$ d'artifice. La vérité a besoin d'être vraisemblable”.
} 
reconstituição de uma narrativa temporalmente linear, mas sim de momentos consideráveis para o delineamento de uma história de vida). A narrativa começa quando o narrador já tem dez anos, sem se mencionar longamente momentos anteriores ao "verão de 63". Entretanto, o autor confirma em depoimento exterior a sua narrativa os diálogos que mantém com suas "personagens", suas tias e a mãe, das leituras que estas fazem de sua(s) obra(s), e como estes diálogos o ajudam a realizar seu trabalho de escritor, o qual "não consiste em dizer os fatos, mas preferencialmente em fazer surgir a emoção de uma situação". (LAFERRIÈRE, 2000, p. 36) Uma das tias do escritor, Raymonde, personagem recorrente em L'Odeur du café e em outros de seus livros, e que, segundo Dany Laferrière, queixa-se frequentemente pelo fato de ele não escrever as coisas "tais quais aconteceram", diz-lhe que distingue dois Danys: "Há o escritor que a impressiona, porque um livro é sagrado para ela. E há o moleque que ela conhece desde o nascimento. E este moleque passa seu tempo roubando as vidas das pessoas.” (LAFERRIĖRE, 2000, p. 41) Roubando vidas para escrever livros, sessenta por cento sinceros, ou, talvez, próximos à realidade, quarenta por cento, artifício, ou onde começa a capacidade do escritor em pintar a emoção de uma situação e estabelecer um quadro narrado inteligível.

\subsection{Uma escrita naïve}

Em L'Odeur du café, é a criação de imagens, umas após as outras no desfile dos inumeráveis títulos que se sucedem, o recurso usado para organizar os fragmentos de uma infância, construindo um quadro verossímil dos seus caminhos. $\mathrm{O}$ artifício da sinceridade está na construção visualmente organizada da narrativa, na medida em que se compõem quadros definidos e breves para delimitarem-se as cenas. Laferrière dá algumas pistas sobre seu processo de criação ao dizer que "Para L'Odeur du café, por exemplo, vi uma imagem. Uma única. Um pequeno menino sentado aos pés de sua avó numa pequena cidade do interior. Era todo o livro.” (LAFERRIÈRE, 2000, p. 97) Livro em que o autor discorre sobre sua infância sob o ângulo de um período feliz de sua vida, passado sob a larga saia da avó, Da (que reaparece na maioria das suas obras, e, no caso de L'Odeur du café, é figura central).

Os capítulos são bastante curtos e muitíssimo numerosos, todos com títulos e subtítulos, como se se quisesse nomear cada uma das cenas da infância, numa tentativa de melhor apreendê-la, ou ao menos descrevê-la, sempre começando por um título que anuncia e atualiza a cena revivida. O próprio autor diz em outro texto: "Quero perder a cabeça. Voltar a ser um moleque de quatro anos. Ei, um pássaro atravessa meu campo de visão. Escrevo: pássaro. Uma manga cai. Escrevo: manga. As crianças jogam bola na rua entre os carros. Escrevo: crianças, bola, carros” (LAFERRIÈRE, 1999, p. 14) ${ }^{15}$.

Tanto as situações quanto as personagens vão e voltam todo o tempo, sob os diversos títulos, exigindo do leitor que ele reestabeleça a coesão da narrativa, costurando frequentemente os diversos fragmentos para recompor a(s) sequência(s) da narração, dispersas pelos vários capítulos, e marcada(s) pela oralidade predominante do discurso, que se constrói a partir de uma espécie de escritura da fala: "Seus textos [de Laferrière] têm uma aparência sincopada e elíptica que se aproxima da reportagem ou de

\footnotetext{
15 "Je veux perdre la tête. Redevenir un gosse de quatre ans. Tiens, un oiseau traverse mon champ de vision. J'écris: oiseau. Une mangue tombe. J'écris: mangue. Les enfants jouent au ballon dans la rue parmi les voitures. J'écris: enfants, ballon, voiture".
} 
respostas de entrevista traduzidas de uma língua estrangeira. A escritura de Laferrière adquire um valor [...] nem totalmente americano, nem tipicamente francês do Quebec, nem absolutamente haitiana [...]" (MOISAN, 2004, p. 101) ${ }^{16}$. Vejamos um exemplo desta linguagem com a primeira descrição de uma das personagens que ocupam um papel de destaque para o narrador, Vava, seu primeiro amor de infância: "Je ne l'ai pas vue venir. Elle est arrivée dans mon dos, comme toujours. Elle revenait de la messe de l'après-midi avec sa mère. Vava habite en haut de la pente. Elle porte une robe jaune. Comme la fièvre du même nom" (LAFERRIÈRE, 2001, p. 19). A descrição se dá por frases curtas, sem o uso, por exemplo, da conjunção "e" ou de pronomes relativos que pudessem ligá-las numa composição de períodos longos; o resultado é uma linguagem realmente próxima a uma reportagem, marcada pela enumeração das sequências da cena. Em outro exemplo: “Un jour, j’ai demandé à Da de m'expliquer le paradis. Elle m'a montré sa cafétière. C'est le café des Palmes que Da préfère, surtout à cause de son odeur. L'odeur du café des Palmes. Da ferme les yeux. Moi, l'odeur me donne des vertiges" (LAFERRIÈRE, 2001, p. 21), além da habitual sucessão de frases curtas, o autor emprega também a ausência de verbo ("L'odeur du café des Palmes"), e a frase sincopada, "Moi, l'odeur me donne des vertiges", de forma que o efeito produzido caracteriza-se pela impressão de rapidez e de concisão. Quando questionado acerca de seu estilo, elíptico e sincopado, Laferrière (2000, p. 44) diz desejar "atingir a ausência de todo estilo. Nenhum traço. Que o leitor esqueça as palavras para ver as coisas". A grande ironia é que a busca pela ausência de estilo, é, por si mesma, um estilo. Isto é, a escolha pela palavra "simples" e banal, pelas frases curtas, assim como o apelo à criação de imagens, é um estilo. Assim, o escritor pinta as cenas da sua infância, os hábitos e crenças dos habitantes da pequena cidade, o dia a dia, a paisagem e o clima, as sensações infantis como o primeiro amor de infância, e as inúmeras personagens que aparecem, reaparecem, e desaparecem ao longo da narrativa, num estilo de escritura próximo ao da pintura naif ${ }^{17}$, da qual o Haiti é um dos maiores expoentes, com artistas do povo nas ruas, nos mercados e feiras, enfim, por toda parte.

Vejamos a que universo remete a arte naif, também chamada de ingênua, de art premier ou primitiva, embora alguns críticos de arte, como Paulo Klein (2004), alertem para o perigo de se rotular uma produção artística, visto que a arte naif designa as obras de artistas, frequentemente autodidatas, em desacordo com as correntes artísticas de seu tempo (por falta de jeito ou por ignorar as produções acadêmicas). A arte naïf designa também uma escola de pintura, nomeada "peintres naïfs", defendendo um estilo figurativo caracterizado, sobretudo, pelo emprego de cores alegres (em tintas planas), e uma representação "ingênua" de assuntos populares (como paisagens campestres, costumes folclóricos e animais). Para Jacqueline Finkelstein (2004, p.11), diretora do Museu Internacional de Arte Naif do Brasil (MIAN), os autodidatas da pintura naif são "contadores pictórios de histórias", que "pintam molhando os pincéis no coração". Já Klein, ao remeter o estilo a um universo mais acadêmico, aponta que:

\footnotetext{
16 “Ses textes ont une allure syncopée et elliptique qui s'apparente à du reportage ou à des réponses d'interview traduites d'une langue étrangère. L'écriture de Laferrière prend une valeur [...] ni totalement américaine, ni typiquement française du Québec, ni tout à fait haïtienne".

${ }_{17}$ Mantém-se frequentemente em português o adjetivo no gênero masculino do francês, naïf, ao invés do feminino, naïve. Assim, diz-se por exemplo em português "Museu Internacional de Arte Naif do Brasil (MIAN)".
} 
Óbvio que o termo naïf ou naïve não é de fácil interpretação. Desde que surgiu como definição de um estilo, o termo usado primeiramente por Alfred Jarry (1873-1907) para identificar o universo ingênuo e harmonioso de Henry "Douanier" Rousseau (1844-1910), artista admirado por Picasso (1881-1973), Matisse (1869-1954), Kandinsky (1866-1944) e outros, o universo naif se ampliou [...] por onde passou, foi adotado e angariou entusiastas ingênuos e hábeis comerciantes, intelectuais de vanguarda e leigos apaixonados. (KLEIN, 2004, p.9)

Ao pincelar o universo da pintura naif, Filkelstein enfatiza o caráter popular e autodidata do estilo, fortemente marcado pelo uso das cores planas, frequentemente vermelho, amarelo e azul (embora o uso destas cores seja um elemento facilmente recorrente, mas não uma regra de definição):

A pintura naif, realizada por autodidatas dotados de um tino plástico natural e sem as delimitações da arte acadêmica ou outras, tem como característica a total liberdade de criar.

Ingênuos, puros, livres e sem compromissos, espontâneos, sonhadores, críticos, delatores e poetas, os naïfs buscam, em geral, no âmago de suas emoções, a forma e a cor para recobrir o suporte da sua arte. Tendo como intenção prioritária, expressar o que sentem.

[...] os naïfs relatam através de seus pincéis, o etéreo mundo dos sonhos e desejos, as lendas, “causos” e tradições populares, por vezes delatando também, quando necessário, a crueldade do ser humano. (FILKELSTEIN, 2004, p. 11)

Laferrière diz que sua escrita, assim como na pintura naïf, em que não há ponto de fuga nos quadros (visto que as tintas são planas na maioria deles e, por isto mesmo, é o quadro que penetraria no observador, e não o observador no quadro), invade o leitor:

Os pintores haitianos me deram minha maior lição estética. E é verdade que, quando escrevo, tento fazer como eles, isto é, tento intoxicar o leitor de maneira que ele não possa pensar em um outro universo além daquele que lhe proponho. Eu o invado. [...] Quando você está diante de um bom quadro primitivo (adoro a palavra primitivo), o universo que lhe é proposto não é um universo de análise (LAFERRIÈRE, 2000, p. $104)^{18}$.

Em outro de seus romances, Pays sans chapeau, o próprio autor se declara um "écrivain primitif" ao dizer: "Escrevo a céu aberto no meio das árvores, das pessoas, dos gritos, dos choros [...] em torno de mim, tudo vai tão lentamente. [...] Dir-se-ia um pintor primitivo. É isto, encontrei. Eu sou um escritor

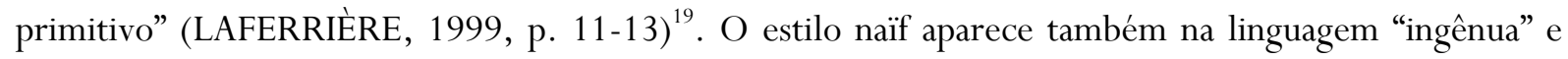
oral empregada por Laferrière, como vimos, com frases curtas e elípticas, que procuram dar ao seu texto em L'Odeur du café um estilo intenso e fluido como cores alegres numa paisagem simples de céu azul, mar, e pés vagarosos: "o farniente, o interior, as ruas ensolaradas e vazias, pessoas tomando um café sob uma mangueira por volta das duas horas da tarde, o mar turquesa do Caribe, uma arte de viver que

\footnotetext{
18 “Les peintres primitifs haïtiens m'ont donné ma plus grande leçon esthétique. Et c'est vrai que, quand j'écris, je tente de faire comme eux, c'est-à-dire que j'essaie d'intoxiquer le lecteur de façon qu'il ne puisse penser à un autre univers que celui que je lui propose. Je l'envahis. [...] Quand vous êtes devant un bon tableau primitif (j'adore le mot primitif), l'univers qui vous est proposé n'est pas un univers d'analyse".

19 "J'écris à ciel ouvert au milieu des arbres, des gens, des cris, des pleurs (...) autour de moi, tout va si lentement. On dirait un peintre primitif. Voilà, c'est ça, j’ai trouvé. Je suis un peintre primitif."
} 
ainda mora em mim. A infância!" (LAFERRIÈRE, 2000, p. 74) ${ }^{20}$. Para entendermos melhor o estilo naïf do autor, tomemos como exemplo a seguinte descrição de L'Odeur du café:

On dirait un dessin de peintre naif avec, au loin, de grosses montagnes chauves et fumantes. Là-haut, les paysans ramassent le bois sec pour le brûler. Je distingue les silhouettes d'un homme, d'une femme et de trois enfants dans le coin du vieux morne. L'homme est en train de faire un feu à trois pas de sa maison, une petite chaumière avec une porte et deux fenêtres. La femme vient de rentrer dans la maison d'où elle ressort immédiatement pour aller se placer devant l'homme. Elle lui parle en faisant de grands gestes avec les bras. Une fumée noire et épaisse monte vers le ciel bleu clair. L'homme ramasse un paquet de brandilles qu'il jette dans le feu. La flamme devient plus vive. Les enfants courent tout autour de la maison. La femme les fait entrer et retourne de nouveau vers l'homme. Le feu est entre les deux.

Je raconte tout cela à Da. Il faut dire que je raconte tout à Da. Da dit que j'ai un oeil d'aigle. (LAFERRIÈRE, 2001, p. 16)

Laferrière descreve desta maneira, logo na segunda página de sua narrativa, o cenário da sua infância, passada em grande parte em Petit Gôave, no Haiti. A paisagem é diretamente associada com a pintura naif: as grandes montanhas e o céu azul claro destacam o cenário de uma cena comum no dia a dia da pequena cidade, com personagens comuns, camponeses juntando lenha, crianças brincando ao redor da casa, uma mulher falando com grandes gestos, um homem jogando gravetos no fogo; uma fumaça negra e espessa se delineia, a chama entre os dois, o fogo entre os dois, e, subitamente, a "cena" para. Chega ao fim a descrição. O quadro está pintado, sem a necessidade de um universo de análise por parte do narrador, que, simplesmente, a observa. Eis a cena "bruta", naïve, expressa pela sequência de frases curtas, sem qualquer comentário indicando o julgamento ou a apreciação do "olho de águia" que se fixa nela.

\subsection{Onde está a língua crioula?}

Em L'Odeur du café, predomina a (re)construção de uma infância feliz, em que não aparecem explicitamente conflitos ou lacunas referentes a uma identidade social, linguística ou conceitual. Em momento nenhum da narrativa se fala sobre a existência de outra(s) língua(s) local(ais), como o crioulo, além da língua francesa (oficial), nem de possíveis conflitos linguísticos ou culturais. Não aparece na narrativa um questionamento cultural ou histórico em relação às possíveis feridas de um país portador de uma história de colonização e independência da metrópole francesa. Quanto a isto, o escritor diz: "É preciso se lembrar que o Haiti é um país ainda muito orgulhoso por ter sido a primeira república negra do mundo. [...] Não sinto esta dor constante, este sentimento de impotência, que constato nos outros Negros quando estão diante de um Branco" (LAFERRIÈRE, 2000, p. 26-27) ${ }^{21}$.

\footnotetext{
20 "le farniente, la province, les rues ensoleillées et vides, des gens en train de boire du café sous un manguier vers deux heures de l'après-midi, la mer turquoise de la Caraibe, un art de vivre qui m'habite encore. L'enfance, quoi!”.

${ }_{21}$ "Il faut se rappeler que Haïti est un pays encore très fier d'avoir été la première république nègre du monde. [...] Je ne ressens pas cette douleur constante, ce sentiment d'impuissance, que je constate chez les autres Noirs quand ils sont en face d'un Blanc".
} 
Em segundo lugar, referente à língua crioula, que não aparece explicitamente no livro, o autor afirma que

L'Odeur du café é um livro escrito em crioulo. Quando enviei o manuscrito a meu editor, ele me fez observar um fato bem estranho. Se ele compreendia todas as palavras, ele tinha, às vezes, dificuldade para entender o sentido de algumas frases. Retomei imediatamente o manuscrito para terminar descobrindo que era a sintaxe do crioulo. [...] Eu o escrevi em francês, porque a maioria de meus leitores só lê francês. Mas o livro todo estava mergulhado numa cultura haitiana de que o crioulo é a espinha dorsal (LAFERRIÈRE, 2000, p. 180) ${ }^{22}$.

O depoimento do autor confirma o que Vitiello observa como um caráter de intermediação da língua francesa, para "traduzir" o imaginário híbrido de escritores que, como Laferrière, encontram-se entre dois (ou mais) espaços, o haitiano e o do Quebec:

O francês se faz língua intermediária, habitada por outras culturas, de referentes diversos [...] Entretanto, mesmo se o francês serviu para resistir-se frente à ameaça da hegemonia do inglês nos dois espaços, haitiano e do Quebec [...], ele evoca também os traços coloniais contra os quais o crioulo se forjou. O duplo aspecto político do francês é neutralizado e a língua reinventada para tornar-se [...] uma "bi-língua", isto é, uma língua traduzida nela mesma, trabalhada, dobrada, deslocada e de que se pode apropriar-se para fazê-la exprimir um espaço referencial ao qual ela não se destinava ou ao qual não a destinavam (VITIELLO, 1996, p. 351) . $^{23}$.

Em conclusão, L'Odeur du café pode ser caracterizado como uma produção literária e predominantemente autobiográfica, no mínimo, imprevisível. Numa síntese de razões para nossa afirmação, diríamos: primeiramente, por ela escapar recorrentemente, como vimos, a muitos dos procedimentos que caracterizam uma obra autobiográfica; além disto, os traços de oralidade, o imaginário híbrido de Laferrière e, sobretudo, a estética fortemente naïve da obra invadem, ou melhor, arrebatam o leitor, levando-o a um universo de cores e odores (não apenas de café) em um apelo sinestésico de construção de sentidos diversos, por meio de uma língua francesa reinventada.

\footnotetext{
22 “L'Odeur du café est un livre écrit en créole. Quand j'ai envoyé le manuscrit à mon éditeur, celui-ci m’a fait remarquer un fait assez étrange. S'il comprenait tous les mots, il peinait quelquefois à comprendre le sens de certaines phrases. J'ai repris tout de suite le manuscrit pour finir par découvrir que c'était la syntaxe du créole. [...] Je l'ai écrit en français parce que la grande majorité de mes lecteurs ne lisent que le français. Mais tout le livre se trouvait baigné dans une culture haïtienne dont le créole est l'épine dorsale".

23 "Le français se fait langue intermédiaire, habitée par des cultures autres, aux référents divers (...) Cependant, même si le français a servi à résister face à la menace d'hégémonie de l'anglais dans les deux espaces, haïtien et québécois (...), il évoque aussi les traces coloniales contre lesquelles le créole s'est forgé. Le double aspect politique du français est neutralisé et la langue réinventée pour devenir (...) une "bi-langue", c'est-à-dire une langue traduite en elle-même, travaillée, pliée, détournée et que l'on peut s'approprier pour lui faire exprimer un espace référentiel auquel elle ne se destinait pas ou auquel on ne la destinait pas."
} 


\section{Referências bibliográficas}

BAKHTIN, M. Estética da criação verbal. São Paulo: Martins Fontes, 2006.

BARBERY, M. et alii. Pour une « littérature-monde » en français. Le Monde des Livres. 16 mars 2007. p. 2

BOURDIEU, P. "A ilusão biográfica”. In: FERREIRA, M. M. e AMADO, J. (org.) Usos e abusos da história oral. Rio de Janeiro: Fundação Getúlio Vargas, 1996.

CHAMOISEAU, P. Une enfance créole I - Antan d'enfance. Paris: Gallimard, 1990.

COLLÈS, L. e LEBRUN, M. La littérature migrante dans l'espace francophone Belgique - France - Québec Suisse. E.M.E. Éditions, 2007.

FILKELSTEIN, J. A. "Liberdade na expressão criativa”. In: Bienal Naïfs do Brasil 2004, São Paulo: SESC SP, 2004.

FREUD, S. "Leonardo da Vinci e uma lembrança da sua infância". In: Cinco lições de psicanálise; Leonardo da Vinci e Outros Trabalhos. Edição Standard Brasileira das Obras Completas de Sigmund Freud, volume XI. Rio de Janeiro, Imago, 1969.

GOHARD-RADENKOVIC, A. "De l'usage des concepts de "culture" et "d'interculturel" en didactique ou quand l'évolution des conceptions traduit l'évolution de la perception sociale de l'autre”. In: BERTRAND, O. (dir.) Diversités culturelles et apprentissage du français; Approche interculturelle et problématiques linguistiques. Paris: École Polytechnique, 2005.

KLEIN, P. “O espírito espontâneo da arte”. In: Bienal Naïfs do Brasil 2004, São Paulo: SESC SP, 2004.

LAFERRIÈRE, D. Pays sans chapeau. Paris: Le Serpent à Plumes, 1994. J'écris comme je vis. (Entrevista com Bernard Magnier). Paris: La passe du vent, 2000.

VLB).

LAZURE, S. e ROYER, A. Dany Laferrière - Un auteur d'Amérique (Dossier de recherche présenté par André Royer et Stéphanie Lazure), 2006. Disponível em:

<http://www.contacttv.net/i_dossier_recherche_contenu.php>. Acesso em 10 maio 2009.

LEBRUN, M. "A literatura no ensino do Francês Língua Estrangeira (FLE): comprometer-se com convicção". In: Horizontes de Lingüística Aplicada. Brasília: Instituto de Letras, Programa de PósGraduação em Lingüística Aplicada/UnB, vol. 6, n.1, 2007.

LEJEUNE, P. Les brouillons de soi. Paris: Éditions du Seuil, 1998. L'autobiographie en France. Paris: Armand Colin, 2004.

MOISAN, C. "L'écriture de l'exil des écrivains migrants du Québec: de la dualité à l'expression d'une identité culturelle". In: Le français dans le monde - Altérité et identités dans les littératures de langue française, número especial, julho 2004. Paris: Clé international, 2004.

MOREIRA, H. Traduzindo uma obra crioula: Pays sans chapeau de Dany Laferrière. Dissertação de mestrado defendida junto ao programa de Pós-Graduação em Francês - DLM-USP, 2006 (inédita).

VITIELlO, J. "Poétiques haïtiennes-québécoises: D. Laferrière, É. Ollivier et G. Étienne". In: LAURETTE, P. e RUPRECHT, H.-G. (dir.) Poétiques et imaginaires; Francopolyphonie littéraire des Amériques. Paris: L'Harmattan, 1996.

\section{Sitografia:}

www.contacttv.net

www.museunaif.com.br

www.pauloklein.art.br/binaif.htm 


\section{Agradecimentos:}

A minha orientadora de mestrado, $\operatorname{Prof}^{\mathrm{a}} \operatorname{Dr}^{\mathrm{a}}$ Cristina Moerbeck Casadei Pietraróia, por todo o respeito, doçura e responsabilidade, inesquecíveis.

À Prof ${ }^{a} \operatorname{Dr}^{a}$ Diva Bárbaro Damato, que abriu as portas e o horizonte das literaturas de expressão francesa a uma jovem que mal conhecia o próprio bairro.

Referência eletrônica: SOBRINHO, Ataiena V. da L. Miguel. A narrativa autobiográfica de infância: arrebatados pelos sentidos em L'odeur du café, de Dany Laferrière, Revista Criação \& Crítica, n. 4, p. 103-118, 2010. Disponível em: <http://www.fflch.usp.br/dlm/criacaoecritica/dmdocuments/09CC_N4_ASobrinho.pdf> 